\title{
Estimation of Genetic Parameters for Growth Performance and Survival Rate in a Clonal Test of Peronema canescens
}

\author{
Kyu-Suk Kang ${ }^{1 *}$, Mu-Seok Han $^{2}$, In-Sik Kim ${ }^{2}$, Song-Hee $\mathrm{Nam}^{3,4}$ \\ ${ }^{1}$ Department of Forest Sciences, Seoul National University, Seoul 151-742, Republic of Korea \\ ${ }^{2}$ Department of Forest Genetic Resources, Korea Forest Research Institute, Suwon 441-847, Republic of Korea \\ ${ }^{3}$ Department of Forest Resources, Kangwon National University, Chuncheon 200-701, Republic of Korea \\ ${ }^{4}$ Permanent address: Korea Forest Service, Daejeon 302-701, Republic of Korea
}

\begin{abstract}
Quantitative genetic parameters were estimated for three characters that are important to timber production and survival of Peronema canescens planted in West Java and Central Kalimantan, Indonesia. Significant clonal variation was detected for tree height, diameter at breast height (DBH) and survival rate among 150 clones of $P$. canescens by age of four years. Clonal survival rates were, on average, $47.8 \%$ in West Java and $29.2 \%$ in Central Kalimantan. The averages of tree height and DBH in Central Kalimantan were higher than those in West Java (4.71 m vs. $1.30 \mathrm{~m}$ in height and $8.73 \mathrm{~cm}$ vs. $1.72 \mathrm{~cm}$ in DBH). Tree height growth was significantly correlated with DBH growth whereas rank correlation of growth trait between sites was weak and non-significant. Highly significant differences in height, DBH growth and survival were observed among sites and between clones. The broad sense heritability was estimated separately in each site which was shown to be under moderate genetic control. Expected genetic response was estimated as a percentage of test mean in tree height and DBH growth after one generation of selection. The genetic response for tree height was expected to be $11.5 \%$ in Java and $12.8 \%$ in Kalimantan when the best $50 \%$ of superior clones were selected and used in a planting program. This result suggests that genetic improvement of growth traits through clone selection in P. canescens would be possible. The genetic gain could result in substantial returns if a large planting program would be developed.
\end{abstract}

Keywords Genetic parameters, Heritability, Correlation, Genetic gain, Progeny test

\section{INTRODUCTION}

Peronema canescens Jack, known as 'false elder' in English and 'sungkai' in Indonesian, is native to Peninsular Malaysia, Sumatra, the Riau Archipelago, West Java and Central Kalimantan. It is cultivated in Indonesia, Malaysia and Thailand. It may have been introduced into Java from Sumatra but is now fully naturalized. Peronema canescens is a local pioneer species which is fire tolerant and economically attractive to local people (Tolkamp et al. 2000; GRIN 2007).

Sungkai is an evergreen or deciduous shrub or small to medium-sized tree, which can reach up to $20-30 \mathrm{~m}$ tall. The bole is straight or slightly flexuous, branchless for up to 9-15 $\mathrm{m}$, measuring up to $70 \mathrm{~cm}$ in diameter and usually with small buttresses. The root system is superficial and with a short taproot. The surface of the bark is dirty grey or light buff, smooth to fissured and fibrous or scaly. The crown is ovoid, with 4-angled twigs and densely short-hairy (Willis 1973; Richter and Dallwitz 2009).

$P$. canescens is one of the fancy woods of Indonesia, which belongs to a number of high timber quality species recommended by The Indonesian Ministry of Forestry for use in the development of industrial forest plantations (IFP). The IFPs are carried out in response to an increasing wood demand and aim at reducing pressure on the natural forests, thereby contributing to national land conservation objectives, as well as to the supply of industrial raw materials (Hatta 1999).

The wood of $P$. canescens is used in various ways from roof trusses to more specific purposes in the village. The attractive grain makes it suitable for veneer, furniture and

Received August 21, 2013; Revised September 25, 2013; Accepted September 25, 2013; Published September 30, 2013

*Corresponding author Kyu-Suk Kang, kangks84@snu.ac.kr, Tel: +82-2-880-4753, Fax: +82-2-873-3560 
cabinetwork (Martawijaya et al. 1981). Hence, $P$. canescens has the potential to be planted by local people on their land for their own use and as a cash crop, in addition to IFPs for industrial purposes (Hatta 1999).

Although $P$. canescens is used in IFPs in Indonesia, no efforts have been made yet to develop the quality of planting stock. Generally, availability rather than quality of cuttings in a site is considered. Not all vegetative propagation nurseries or seed sources are managed professionally by private or official sectors. Genetic variation in wild populations is virtually unknown, and few attempts have been made in genetic improvement. The Indonesian government has made forest rehabilitation a priority, namely national land and forest rehabilitation movement (GERHAN), considering the current condition of forest resources. The primary goal of GERHAN is to rehabilitate degraded land and forest to keep the remaining natural forests (RSSNC 2007).

A tree improvement program of $P$. canescens has not yet initiated in Indonesia. So, the Korea Forest Research Institute has been supporting tree breeding works in Indonesia by collaborating with the Ministry of Forestry, Indonesia and the Korea International Cooperation Agency since 2005, with the Project on 'Seed Sources and Nursery Technology Development in Indonesia (2005-2010)'.

Background of the present study is the SSNTDP's emphasis on applied forest research and support of research on how to select and improve the forest reproductive materials in Indonesia. Part of the project sought to improve the forestry situation by investigating suitable seed sources and tree species for the restoration and suitable management of the forests.

This paper reports growth performances and genetic parameters from the cutting trails of $P$. canescens clones, which were established in West Java and Central Kalimantan, Indonesia. The objectives of this study were to examine the survival rate of 150 clones from trees selected, to estimate genetic parameters (heritability, correlations, etc) of tree height and DBH growth traits, to determine expected genetic gain by selecting superior clones, and to identify suitable vegetative sources for reforestation in West Java and Central Kalimantan, Indonesia.

\section{MATERIALS AND METHODS}

\section{Parent selection and progeny trial}

A total of 150 Peronema canescens trees growing in several populations in Java, Sumatra and Kalimantan, Indonesia were selected. Growth, tree form, stem straightness, cylindrical shape, disease/insect resistance and seed availability were all taken into account in the parental selection. To reduce the likelihood of genetic relatedness, the trees were separated by a minimum of 100 meters.

The field tests of the 150 cutting clones were established in West Java and Central Kalimantan in Indonesia. Openpollinated seeds were collected but did not germinate well thus stem cuttings were taken from the selected plus trees and propagated by the seed research teams of Bogor Agricultural University (IPB) and Gadja Mada University (GMU). The stem cuttings which were about 20 to $25 \mathrm{~cm}$ in length were planted in poly-bags directly. The medium was composed of top soil, organic fertilizer and clay soil (1:1:1). After sprouting, the poly bags were placed on nursery beds where they were arranged in a randomized complete block design. Cuttings were grown for two months (December 2006 to January 2007) in local nurseries at Gunung Walat nursery of IPB.

Establishment started at the beginning of February 2007 in West Java and Central Kalimantan, Indonesia. Cuttings were transplanted within a week. Weeding was carried out four times during the first year and three times after. On the nursery and planting site, the plants were grown in a randomized block design with seven blocks. Within a block, each clone was represented by a four-tree row plot and the spacing was $2.5 \mathrm{~m} \times 2.5 \mathrm{~m}$ in the field trial. Growth traits such as tree height and diameter at breast height (DBH), and survival rate were evaluated four years after establishment.

\section{Statistical and genetic analyses}

Differences of growth performance among clones were examined using the general linear model (GLM) of SAS ${ }^{\circledR}$ software (SAS Institute Inc. 1989). The following model was used for analysis of variance (ANOVA) for growth characters at the test sites by a fixed effect model (Lin and Zsuffa 1993) as: 


$$
Y_{i j k l}=m+S_{i}+C_{j}+B_{(s) k}+(S C)_{i j}+(C B)_{j k}+(S C B)_{i j k}+e_{l(i j k)}
$$

where $Y_{i j k l}$ is the observation of the $l^{\text {th }}$ tree of the $j^{\text {th }}$ clone $(C)$ in the $k^{\text {th }}$ block $(B)$ at the $i^{\text {th }}$ site $(S), m$ is the overall mean, $(S C)_{i j}$ is the interaction between $i^{\text {th }}$ site and $j^{\text {th }}$ clone, $(C B)_{j k}$ is the interaction between $j^{\text {th }}$ clones and $k^{\text {th }}$ block $(B)$, and $(S C B)_{i j}$ is the plot error and $e_{l(i j k)}$ is the within-plot error.

For each site, the analysis of variance for growth characters was employed as follows:

$$
Y_{i j k}=m+C_{i}+B_{j}+(C B)_{i j}+e_{k(i j)}
$$

where $Y_{i j k}$ is the observation of the $k^{\text {th }}$ tree of the $i^{\text {th }}$ clone $(C)$ in the $j^{\text {th }}$ block $(B), m$ is the overall mean, $(C B)_{i j}$ is the interaction between $i^{\text {th }}$ clone and $j^{\text {th }}$ block and $e_{k(i j)}$ is the within-plot error.

Broad sense heritabilities $\left(h_{f}^{2}\right)$ of clonal mean at each site were estimated as follows:

$$
h_{f}^{2}=\frac{\sigma_{c}^{2}}{\sigma_{c}^{2}+\sigma_{c b}^{2} / b+\sigma_{e}^{2} / n b}
$$

where $\mathrm{s}_{c}{ }^{2}, \mathrm{~s}_{e}{ }^{2}$ and $\mathrm{s}_{c b}{ }^{2}$ are the variances of clone, error and interaction, $n$ is the harmonic mean of the number of trees per plot and $b$ is the number of block.

In order to determine to what extent the variation in one trait is associated with that in others, Pearson's and Spearman's correlations were estimated between pairs of traits.

Expected genetic response $(\Delta G)$ was estimated as a percentage of test mean in tree height and DBH growth after one generation of selection, as follows:

$$
\Delta G=h^{2} S=i h_{f}^{2} \sigma_{P}
$$

where $h_{f}^{2}$ is the clone heritability, $S$ is the selection differential, $i$ is the intensity of selection taken in Becker (1984), and $\sigma_{P}$ is the phenotypic standard deviation (Falconer 1981).

\section{RESULTS AND DISCUSSION}

\section{Growth performance and genetic variation}

A large variation in height and DBH among clones at the test sites was observed (Table 1). The grand mean height of 4-year-old P. canescens were $1.30 \mathrm{~m}$ and $4.71 \mathrm{~m}$, and those

Table 1. Grand mean and range of height and DBH growth, and percent survival of 150 of $P$. canescens by age of four years in West Java and Central Kalimantan, Indonesia.

\begin{tabular}{lccc}
\hline \hline \multicolumn{1}{c}{ Site } & Height $(\mathrm{m})$ & DBH $(\mathrm{cm})$ & Survival (\%) \\
\hline West Java & $1.30(0.93-1.81)^{*}$ & $1.72(1.03-2.47)$ & $47.8(25.0-78.6)$ \\
Central Kalimantan & $4.71(3.20-6.17)$ & $8.73(4.71-11.7)$ & $29.2(0.0-53.60)$ \\
\hline
\end{tabular}

*range in parenthesis
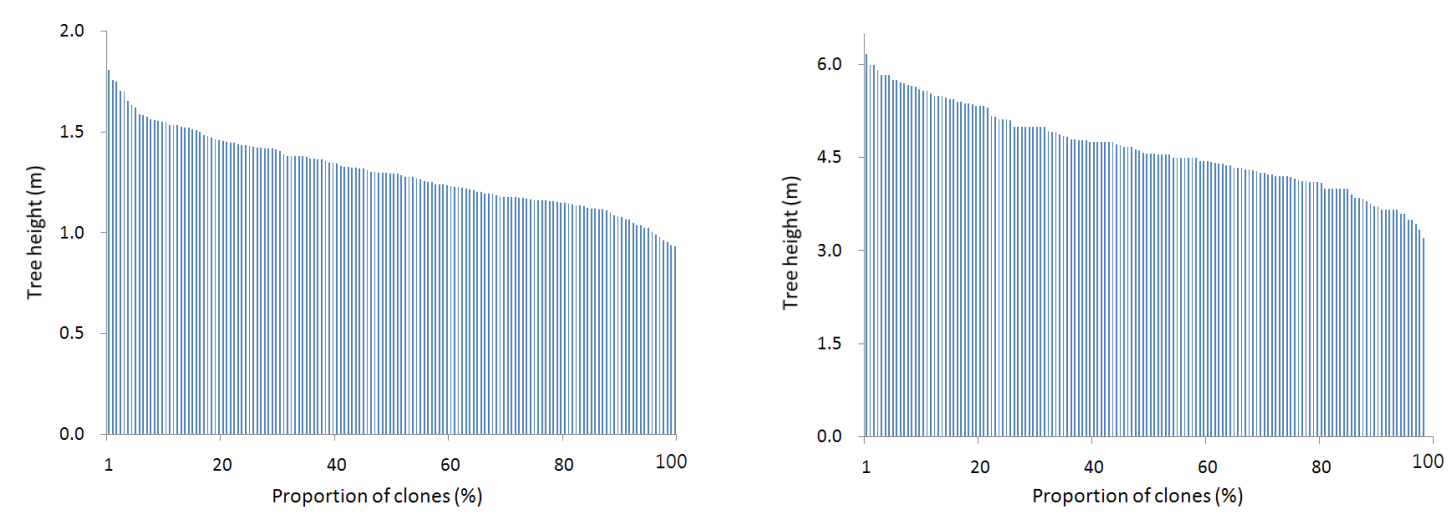

Fig. 1. Variation in height of 150 clones of P. canescens in West Java (left) and Central Kalimantan (right), Indonesia. 
of DBH were $1.72 \mathrm{~cm}$ and $8.73 \mathrm{~cm}$ in West Java and Central Kalimantan, respectively. Trees planted in Central Kalimantan outperformed those in West Java in terms of height (3.6 times higher) and DBH (5.1 times bigger).

The best performing clone in West Java was 95\% better in height and $44 \%$ better in DBH than the worst ones (Fig. 1). Also the best clone in Central Kalimantan outperformed the worst ones with $93 \%$ difference in height and $148 \%$ in DBH (Fig. 2). Identified superior clones exhibited better performance in both parameters consistently in two sites. These selections could be valuable genetic resource for better height and DBH traits in $P$. canescens.

A big difference in the survival rate of 150 clones of $P$. canescens was observed (Table 1, Fig. 3). P. canescens planted in West Java had higher survival rate (47.8\%) than those planted in Central Kalimantan (29.2\%). Two clones in Kalimantan site died by age of four years. The survival rate should thus be continuously monitored in the clonal test trials of $P$. canescens.

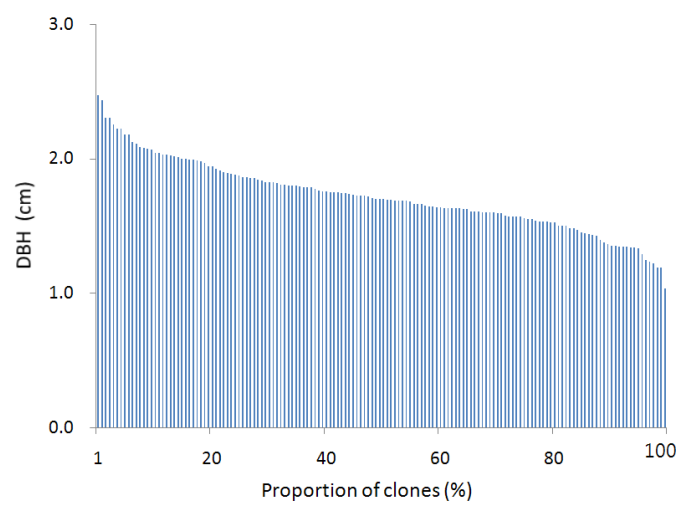

Hatta (1999) reported the initial performance of $P$. canescens provenances in a nursery by 26 months age. It was found that the survival rate varied from $50 \%$ to $95 \%$ among ten provenances and the average survival rate of superior ones was $69 \%$. Also he found out that the Kalimantan provenances dominated the upper group in tree height average, but less in survival rate, which was the same as the result of our study (Figs 1, 2 and 3).

Pearson's correlation coefficients were all positive among traits (height, DBH and survival) in two sites, and were statistically significant between height and DBH and between height and survival in each site (Table 2). In Central Kalimantan, the survival rate was positively correlated with DBH growth.

Spearman's rank correlation coefficients were highly significant for height and DBH growth in West Java and Central Kalimantan sites (Table 2). But the rank correlations of growth traits between sites were very weak and nonsignificant.

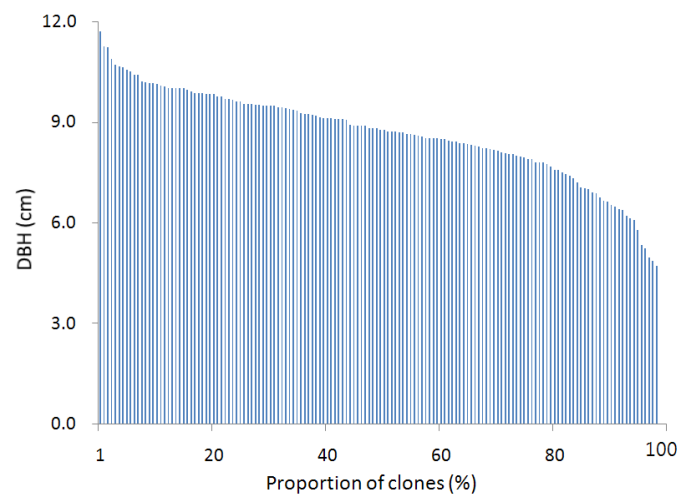

Fig. 2. Variation in DBH of 150 clones of P. canescens in West Java (left) and Central Kalimantan (right), Indonesia.
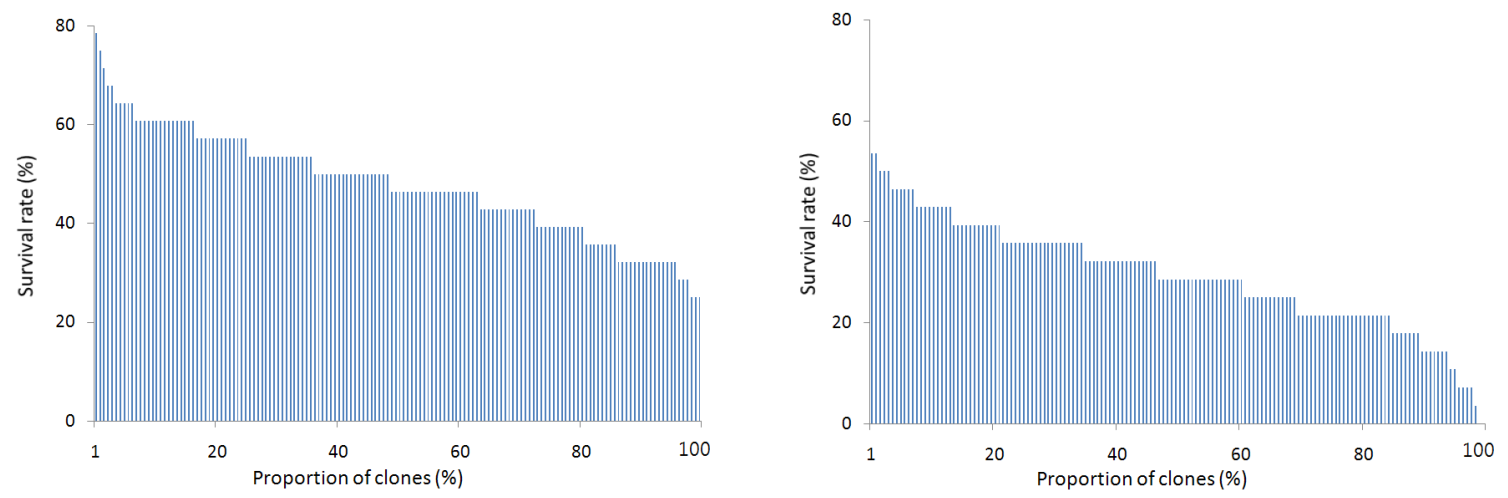

Fig. 3. Difference of survival rate among 150 clones of P. canescens in West Java (left) and Central Kalimantan (right), Indonesia. 
Based on the correlation analysis, tree height might be one of the key criteria for increasing survival and to select superior clones. The condition of climate and soil of the site may also be important in optimizing the mutual adaptability of clone and a new site. A more detailed climatic analysis is needed, both for the original and the new site of the clone in order to assess climatic stress.
Based on AVOVA, highly significant $(\mathrm{p}<0.01)$ differences among two sites, among seven blocks, and between 150 clones were found in all characters of a 4-year-old $P$. canescens (Tables 3, 4). All interaction effects were also statistically significant at 0.01 probability level in both test sites. The block effects were about 15 times larger than clone effect in West Java and eight times larger in Central

Table 2. Pearson's correlation (lower diagonal) and Spearman's rank correlation (upper diagonal) coefficients for growth traits and survival of $P$. canescens clones in West Java and Central Kalimantan.

\begin{tabular}{cccccccc}
\hline \hline \multirow{2}{*}{ Site } & Trait & \multicolumn{3}{c}{ West Java } & \multicolumn{3}{c}{ Central Kalimantan } \\
\cline { 3 - 7 } & & Height & DBH & Survival & Height & DBH & Survival \\
\hline \multirow{2}{*}{ West Java } & Height & - & $0.83^{* *}$ & $0.12^{*}$ & 0.08 & 0.07 & $0.23^{*}$ \\
& DBH & $0.84^{* *}$ & - & 0.02 & 0.11 & 0.03 & 0.20 \\
& Survival & 0.15 & 0.06 & - & 0.01 & 0.02 & 0.01 \\
Central & Height & 0.04 & 0.07 & 0.03 & - & $0.75^{* *}$ & $0.35^{* *}$ \\
Kalimantan & DBH & 0.03 & 0.01 & 0.04 & $0.60^{* *}$ & - & $0.28^{* *}$ \\
& Survival & $0.25^{*}$ & $0.23^{*}$ & 0.06 & $0.25^{*}$ & 0.07 & - \\
\hline
\end{tabular}

$*$ and $* *$ : significant at the probability levels of 0.05 and 0.01 , respectively

Table 3. ANOVA for height of 150 clones at age of four years in the clonal tests of $P$. canescens in West Java and Central Kalimantan, Indonesia.

\begin{tabular}{lccrrl}
\hline \hline Source & $d f$ & \multicolumn{1}{c}{ SS } & MS & $F$ value & \multicolumn{1}{c}{ Expected MS } \\
\hline Site (S) & 1 & $4,110.3$ & $4,110.3$ & $4,389.1^{* *}$ & $\mathrm{~s}_{e}+2.7 \mathrm{~s}_{s b c}+0.2 \mathrm{~s}_{b c}+17.8 \mathrm{~s}_{s c}+0.2 \mathrm{~s}_{c}+2.4 \mathrm{~s}_{b}+2645 \mathrm{~s}_{s}$ \\
Block (B) & 6 & 210.9 & 35.15 & $37.54^{* *}$ & $\mathrm{~s}_{e}+2.7 \mathrm{~s}_{s b c}+5.2 \mathrm{~s}_{b c}+0.2 \mathrm{~s}_{s c}+0.2 \mathrm{~s}_{c}+756.9 \mathrm{~s}_{b}$ \\
Clone (C) & 149 & 278.5 & 1.87 & $2.00^{* *}$ & $\mathrm{~s}_{e}+2.7 \mathrm{~s}_{s b c}+5.2 \mathrm{~s}_{b c}+17.8 \mathrm{~s}_{s c}+35.3 \mathrm{~s}_{c}$ \\
$\mathrm{~S}^{*} \mathrm{C}$ & 149 & 275.2 & 1.85 & $1.97^{* *}$ & $\mathrm{~s}_{e}+2.6 \mathrm{~s}_{s b c}+0.1 \mathrm{~s}_{b c}+17.6 \mathrm{~s}_{s c}$ \\
$\mathrm{~B}^{*} \mathrm{C}$ & 894 & $1,573,9$ & 1.76 & $1.88^{* *}$ & $\mathrm{~s}_{e}+2.6 \mathrm{~s}_{s b c}+5.0 \mathrm{~s}_{b c}$ \\
$\mathrm{~S}^{*} \mathrm{~B}^{*} \mathrm{C}$ & 899 & $1,546.9$ & 1.72 & $1.84^{* *}$ & $\mathrm{~s}_{e}+2.4 \mathrm{~s}_{s b c}$ \\
Error & 3203 & 2999.5 & 0.94 & & $\mathrm{~s}_{e}$ \\
\hline
\end{tabular}

**significant at the 0.01 probability level

Table 4. ANOVA for DBH of 150 clones at age of four years in the clonal tests of $P$. canescens in West Java and Central Kalimantan, Indonesia.

\begin{tabular}{lcccc}
\hline \hline \multicolumn{1}{c}{ Source } & $d f$ & SS & MS & $F$ value \\
\hline Site & 1 & $8,262.2$ & $8,262.2$ & $2,054.8^{* *}$ \\
Block & 12 & $12,744.3$ & $2,124.1$ & $528.3^{* *}$ \\
Clone & 149 & $1,036.5$ & 6.97 & $1.73^{* *}$ \\
Site*clone & 149 & 964.8 & 6.48 & $1.61^{* *}$ \\
Block*clone & 894 & $5,452.7$ & 6.10 & $1.52^{* *}$ \\
Site*block*clone & 899 & $6,244.9$ & 6.95 & $1.73^{* *}$ \\
\hline
\end{tabular}

** significant at the 0.01 probability level 
Table 5. The clonal broad sense heritability $\left(h_{f}^{2}\right)$ for height and DBH growth of 150 clones of 4-year-old $P$. canescens in West Java and Central Kalimantan, Indonesia.

\begin{tabular}{lccc}
\hline \hline & West Java & Central Kalimantan & Combined \\
\hline Tree height & 0.23 & 0.21 & 0.01 \\
DBH & 0.02 & 0.26 & 0.22 \\
\hline
\end{tabular}

Kalimantan site. The clonal variation was small compared to block $\mathrm{x}$ clone and site $\mathrm{x}$ block $\mathrm{x}$ clone variances at both test sites.

Due to the large effects of site and block, the broad sense heritability based on clonal mean was estimated separately in each site. The clonal broad sense heritability estimates $\left(h_{f}^{2}\right)$ ranged from 0.01 to 0.26 (Table 5). The broad sense heritability implied that tree height and DBH traits of $P$. canescens seemed to be under moderate genetic control.

The analysis of height and DBH growth traits revealed that the $P$. canescens clones exhibited considerable genetic variation hence selection of superior clones could be carried out effectively for genetic improvement. As shown in ANOVA, the effect of site was bigger compared to clone effect (Tables 3,4) suggesting the estimation of genetic gain to be done separately on each site.

\section{Expected genetic gain}

The expected genetic gain in height and DBH of a four-year-old $P$. canescens was estimated after one generation of selection. The genetic gain in tree height and DBH could be expected to be $25.9 \%, 20.8 \%, 17.1 \%$ to $2.5 \%$ and 28.4

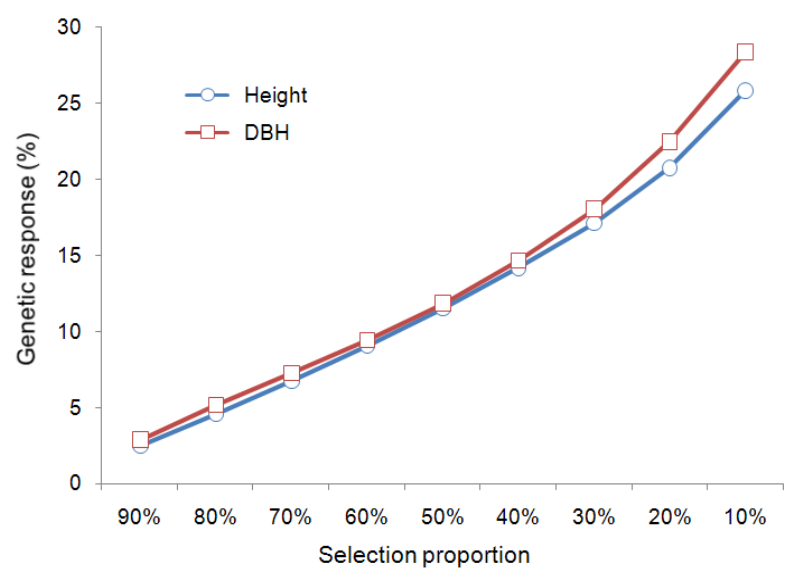

$\%, 22.5 \%, 18.1 \%$ to $2.9 \%$ when the best $10,20,30$ up to 90 percent of superior clones were selected from west Java site and used in a planting program (Fig. 4).

The genetic gains for growth traits at central Kalimantan were also estimated when the superior clones were selected from 10 to $90 \%$ (Fig. 4). The estimated genetic gains of tree height ranged from $3.7 \%$ to $26.3 \%$ and those of DBH ranged from $4.6 \%$ to $24.4 \%$, which were similar to West Java site. This result suggests that genetic improvement of growth traits through clone selection in $P$. canescens would be possible. The genetic gain could result in substantial returns if a large planting program would be developed.

Domestication of $P$. canescens is crucial for the development of a sustainable, high-quality timber resource. Hatta (1992) reported the data from the first field trial of $P$. canescens provenances from various sites, which was established in South Kalimantan, and the results showed a large difference of growth among the provenances. More genetic diversity may be expected over the broad ecological and geographical range of $P$. canescens in Java, Kalimantan and Sumatra. Clearly, research on the provenance and clone of $P$. canescens would lead to genetic improvement

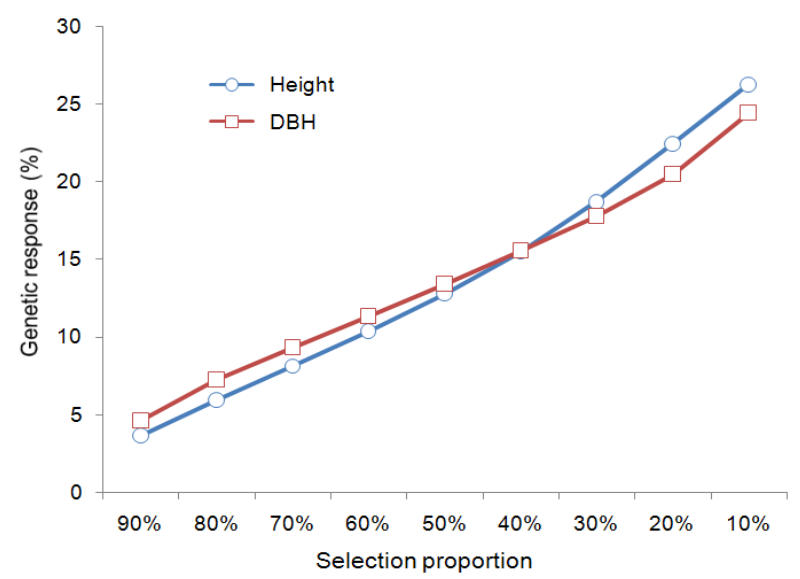

Fig. 4. Expected genetic response when selecting best 10, 20, 30 up to $90 \%$ clone of $P$. canescens for height and DBH traits at age of 4 years in West Java (left) and Central Kalimantan (right), Indonesia. 
and so provide silviculturally optimized populations and clones of P. canescens in the field (Tolkamp et al. 2000; Hardiyanto and $\mathrm{Na}$ 'iem 2001).

\section{Implications for tree breeding}

Genetic variation is not only expressed as differentiation among populations, but is also observed within population. The objective of breeding is to exploit genetic differences between individuals in populations in order to change the expressions of economically relevant traits for increasing plantation yield (Finkeldey and Hattemer 2007).

This study showed that backward selection, on the basis of the variation of cutting performance, could provide substantial improvement on tree height and DBH growth of P. canescens in West Java and Central Kalimantan, Indonesia. Improving tree volume (i.e. height and diameter) is the main objective to be achieved in the breeding program of $P$. canescens. Thus, the breeding objective should focus on the production of improved vegetative materials for operational planting in Indonesia. Continuous field testing would improve the breeding strategy according to the new estimated genetic parameters.

One of the SSNTDP project objectives is to incorporate the early testing procedures into the operational improvement program in West Java and Central Kalimantan, Indonesia. Establishment of clonal seed orchard is thus recommended to get higher genetic gain as quickly as possible. The clonal seed orchard could be developed using cutting of the best clones; backward selection is based on the tree height and DBH performances of their clones (Fig. 5). A hedge orchard can be the other option, which could be established by forward selection of the fastest growing cuttings from the best clones; the best offspring propagated by vegetative propagation from the selected clones. A seedling seed orchard might be an option for long-term breeding, which can be established by collecting seeds from the best clones selected.

\section{CONCLUSION}

This study estimated quantitative genetic parameters of three characteristics that are important for timber production of Peronema canescens in West Java and Central Kalimantan, Indonesia. Significant clonal variations of tree height, DBH and survival were observed among 150 cutting clones of $P$. canescens at age of four years. Highly significant differences in height and DBH growth, and survival rate were also found among clones and between sites. The genetic gain for tree height growth was expected to be $11.5 \%$ in West Java and $12.8 \%$ in Central Kalimantan site if the best 50 percent of superior clone would be selected and used for cutting propagation. The expected genetic gain could give substantial returns for a large-scale planting program.

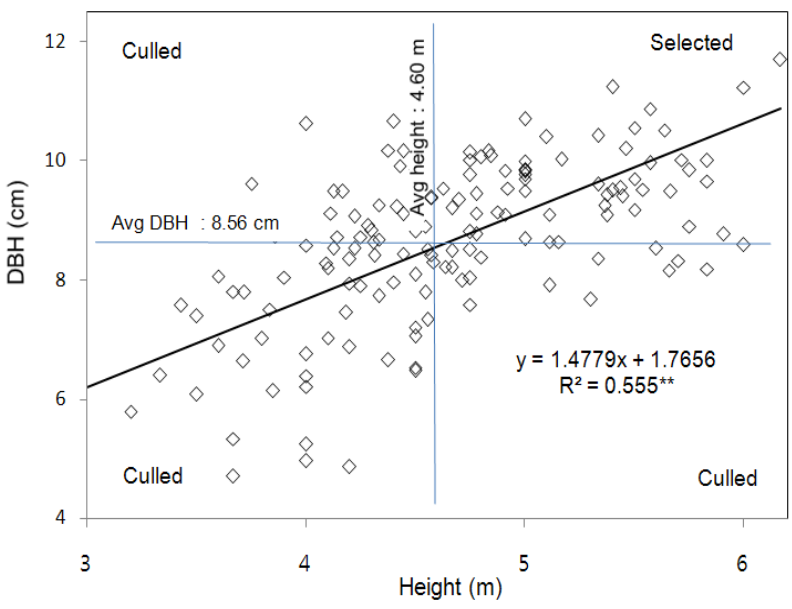

Fig. 5. Regression between tree height and DBH of 150 clones of $P$. canescens at age of 4 years in West Java (left) and Central Kalimantan (right). Straight diagonal lines represent the linear regression curve. 


\section{ACKNOWLEDGMENT}

This study was fundamentally based on the SSNTDP project, which was conducted in the $1^{\text {st }}$ phase $(2005-2007)$ and $2^{\text {nd }}$ phase (2008-2010) within the framework of the co-operation between the Korea International Cooperation Agency and the Ministry of Forestry of Indonesia. This work was also supported by an additional grant from the Korea Forest Research Institute (Project No. FG 0200-2011$03)$ for research co-operation and consultation.

\section{REFERENCES}

Becker WA. 1984. Manual of Quantitative Genetics. Academic Enterprises, Pullman, 4th ed. Washington, USA. pp.43-170.

Falconer DS. 1981. Introduction to quantitative genetics, 2nd edition. London, New York: Longmans. pp.340.

Finkeldey R, Hattemer HH. 2007. Tropical forest genetics (Part B). Springer-Verlag Berlin. pp.109-315.

GRIN. 2007. USDA, ARS, National Genetic Resources Program, Germplasm Resources Information Network. http://www.ars-grin.gov/cgi-bin/npgs/html/paper.pl (25 May 2007).

Hatta GM. 1992. Provenance trial and kinds of cuttings of Peronema canescens Jack in Panaan, South Kalimantan Province. Forestry Faculty of Lambung Mangkurat University. pp. 62.

Hatta GM. 1999. Sungkai (Peronema canescens) a promising pioneer tree: an experimental provenance study in Indonesia. ISBN 905808129X, Wageningen University,
Ph.D. thesis. pp.139.

Hardiyanto EB, Na'iem M. 2001. Present status of conservation, utilization and management of forest genetic resources in Indonesia. Proc. of the SE Asian Moving Workshop on conservation, management and utilization of forest genetic resources. p.15-24. Edit) J. Koskela et al. 2001, Thailand. FORSPA publication No. 21. FAO.

Lin JZ, Zsuffa L. 1993.Quantitative genetic parameters for seven characters in a clonal test of Salix eriocephala. Silvae Genetica 42: 41-46.

Martawiiaya A, Kartasuiana I, Kadir K, Prawira SA. 1981. Indonesian Wood Atlas. Forest Research Product and Development Centre. FORDA. Department of Forestry. Bogor, Indonesia. 1: 141-145.

Richter HG, Dallwitz MJ. 2009. Commercial timbers: descriptions, illustrations, identification, and information retrieval. Version: 25th June 2009. http://delta-intkey. com/wood/en/www/verpecan.htm.

RSSNC, 2007. Genetic material selection and collection for potential plantation - tree improvement in Indonesia. Rumpin seed source and nursery center. pp.34.

SAS Institute Inc. 1989. SAS/Stat User's Guide, Version 6, Fourth Edition, Volume 1, Cry, Nc: SAS Institute Inc., 1989. pp.943.

Tolkamp GW, Priadjati A, Effendi R. 2000. Towards an ecology-based strategy for the reforestation of Imperata cylindrica grasslands in east Kalimantan. In; The balance between biodiversity conservation and sustainable use of tropical rain forests, pp.99-115.

Willis J. 1973. A Dictionary of the Flowering Plants and Ferns. 8th ed. Cambridge University Press, Cambridge, U.K. pp.788. 